Vol. 11 No. 022020

e-issn : 2622-0148, p-issn : 2087-0035

\title{
STUDI LITERATUR HUBUNGAN STRES DENGAN PENERIMAAN DIRI PADA PASIEN ULKUS DIABETIK
}

Literature Study of Correlation Between Stress and Self Acceptance in Diabetic Ulcers Patients

\author{
Sitti Rahmatia, Muhammad Basri, Mardiana Mustafa, Baharuddin, Ainun Nur Zakina \\ Poltekkes Kemenkes Makassar \\ e-mail: mardianamustafa@poltekkes-mks.ac.id
}

\begin{abstract}
Diabetes mellitus is a chronic disease caused by the pancreas that not producing insulin adequately or when the human body cannot use insulin effectively. In Indonesia, there are 10.7 million people with diabetes mellitus and in South Sulawesi, there are 33.693 patients. Diabetic ulcers are a complication of diabetes mellitus in the form of a lesion on the human body that is established by neuropathy and is not controlled, then these diabetic ulcers eventually become psychological stressors for the patients which leads to stress and low self-acceptance. This type of research is a literature study in which the researcher gathers several research articles and then conclude its contents. The purpose of this literature study is to identify any recommendations from previous studies on the correlation between stress and self-acceptance in diabetic ulcer patients. This literature study was compiled by a search of related scientific research articles, in the period 2015 to 2020. 7 articles fit the criteria and then being concluded. The results of the 7 articles researcher can conclude that there is a mutually influential relationship between stress and self-acceptance in patients with diabetic ulcers. Diabetic ulcers are stressors that will psychologically attack patients with weak conditions and ultimately trigger their stress, then the stress would worsen the patient's perception and eventually decreases the quality of their self-acceptance. Then worship, controlling ulcers conditions, and family are the methods used to reduce stress and increase patient self-acceptance.
\end{abstract}

Keywords: Diabetic Ulcer, Stress, Self Acceptance

\begin{abstract}
ABSTRAK
Diabetes melitus merupakan penyakit kronis yang disebabkan karena pankreas tidak memproduksi insulin secara adekuat atau ketika tubuh manusia tidak bisa menggunakan insulin tersebut secara efektif. Di Indonesia terdapat 10,7 juta jiwa penderita diabetes melitus dan di Sulawesi Selatan sendiri terdapat 33,693 ribu jiwa penderita. Ulkus diabetik merupakan komplikasi dari diabetes melitus berupa luka pada anggota tubuh yang diawali oleh neuropati dan tidak terkontrol, kemudian ulkus diabetik tersebut akhirnya menjadi stresor psikologis bagi penderitanya dan menyebabkan stres hingga penerimaan diri rendah. Jenis penelitian ini adalah studi literatur dimana peneliti mengumpulkan beberapa artikel penelitian untuk kemudian disimpulkan isinya. Tujuan dari studi literatur ini adalah untuk mengidentifikasi rekomendasi penelitian-penelitian terdahulu tentang hubungan stres dengan penerimaan diri pada pasien ulkus diabetik. Studi literatur ini disusun atas penelusuran artikel penelitian ilmiah terkait, dalam rentang tahun 2015 sampai 2020. Terdapat 7 artikel yang sesuai dengan kriteria inklusi dan kemudian disimpulkan isinya. Hasil penelitian dari 7 artikel yang dijabarkan dapat ditarik kesimpulan bahwa terdapat hubungan yang saling mempengaruhi antara stres dan penerimaan diri pada pasien ulkus diabetik. ulkus diabetik merupakan stressor yang akan menyerang psikis pasien dengan kondisi tubuh lemah dan akhirnya memicu stres, selanjutnya dampak stres membuat persepsi terhadap diri pasien sendiri menjadi kurang baik dan menurunkan kualitas penerimaan dirinya. Kemudian ibadah, melakukan kontrol terhadap kondisi penyakit, dan keluarga adalah metode-metode yang digunakan untuk mengurangi stres dan meningkatkan penerimaan diri pasien.
\end{abstract}

Kata Kunci: Ulkus Diabetik, Stres, Penerimaan Diri

\section{PENDAHULUAN}

Diabetes melitus merupakan penyakit kronis yang disebabkan oleh karena pancreas tidak memproduksi insulin secara adekuat atau ketika tubuh manusia tidak bisa menggunakan insulin tersebut secara efektif. Insulin itu sendiri merupakan hormone yang bekerja sebegai pengatur kadar gula dalam darah. Peningkatan gula darah, dalam kata lain hiperglikemia merupakan akibat dari diabetes yang tidak dikontrol dan dapat menyebabkan berbagai komplikasi pada sistem-sistem tubuh terutama sistem persyarafan dan pembuluh darah $(\mathrm{WHO}, 2018)$
Menurut rekapan data dari International Diabetes Federation (IDF) tahun 2019, ada 463 juta orang dewasa (20-79 tahun) yang mengidap diabetes melitus dari seluruh dunia. Di pasifik barat dimana Indonesia termasuk di dalamnya, 1 dari 10 orang dewasa menderita diabetes melitus. Di Indonesia sendiri terdapat 10,7 juta jiwa penderita diabetes melitus atau sama dengan 1 setiap 16 orang. Tercatat dalam Laporan Nasional Riskesdas 2018 berdasarkan diagnosis dokter, di Sulawesi Selatan terdapat 33,693 ribu jiwa penderita diabetes melitus dan 23,069 ribu diantaranya adalah orang dewasa. Di Makassar 
sendiri, menurut survei DINKES Makassar pada tahun 2017 terdapat 4,406 kasus baru dan kasus lama 16,755 .

Dilansir dari Prasetyono tahun 2016, Ulkus diabetik merupakan salah satu komplikasi diabetes yang paling umum dijumpai. Umumnya terdapat pada pasien diabetes melitus dengan gangguan neuropati perifer, iskemia, atau kombinasi keduanya. Pada neuropati diabetik, terjadi gangguan saraf sensorik, motorik, dan otonom yang kemudian bermanifestasi berupa kelemahan dan atrofi otot, defisit sensorik yang kemudian berdampak pada penurunan refleks terhadap rangsangan nyeri, tekanan, dan panas yang pada akhirnya berujung pada terjadinya ulkus diabetik

Diabetes melitus, apalagi yang disertai dengan komplikasi ulkus sedikit banyak sangat mempengaruhi kondisi psikis penderitanya. Pasien dengan ulkus diabetik akan mengalami gangguan citra tubuh, hal tersebut akan menimbulkan emosi yang negatif sehingga penderita membutuhkan penerimaan diri yang baik agar dapat menjalani kehidupan dengan stabil (Silalahi, 2016). Penerimaan diri atau self acceptance adalah sikap yang pada dasarnya merasa puas dengan diri sendiri, kualitaskualitas dan bakat-bakat, dan pengakuan akan keterbatasan-keterbatasan sendiri (Chaplin, 2012). Pasien diabetes dengan komplikasi ulkus akan menjadi rentan terhadap stres dan membuat perasaan tidak nyaman sehingga persepsi diri akan menurun dan penderitanya akan kesulitan menjalankan aktivitas sosial (Mulis, 2015)

Pada penelitian yang berjudul korelasi penerimaan diri dengan stres pada pasien diabetes oleh Yhani dkk, tahun 2012 didapatkan hasil bahwa terdapat korelasi yang negatif terhadap penerimaan diri dengan stres. Yhani kemudian menambahkan bahwa stres merupakan reaksi psikis dan fisik terhadap stimulus dari luar

(stresor) yang mengancam dan menuntut adanya penerimaan diri terhadap stresor tersebut. Pada kasus di penelitian ini, stresor yang dimaksud adalah ulkus diabetik. Pasien dengan ulkus diabetik ini sedikit banyak akan menganggap penyakitnya sebagai beban dan lama kelamaan pasien akan menjadi stres sehingga mempengaruhi langsung penerimaan dirinya.

Berdasarkan uraian di atas, peneliti tertarik untuk meneliti hubungan stres dengan penerimaan diri pada pasien dengan ulkus diabetik

\section{METODE}

Jenis penelitian ini adalah penelitian studi literatur. Dimana penelitian jenis ini peneliti diharuskan untuk mencari dan mengumpulkan berbagai jurnal dan artikel dan kemudian disimpulkan menjadi argumen untuk memperkuat data penelitian.

Sumber data pada penelitian ini adalah data sekunder, data ini merupakan data yang diperoleh secara tidak langsung. Data ini diambil dari dokumendokumen yang berkaitan dengan penelitian. Dokumen-dokumen tersebut diperoleh melalui data tertulis ataupun dengan mengakses situs-situs yang memuat gambaran mengenai informasi yang menunjang dalam menyelidiki hubungan penerimaan diri dengan stres pada pasien ulkus diabetik

Pengambilan data dilakukan melalui studi pustaka dengan cara melakukan penelusuran hasil publikasi ilmiah dengan rentang tahun 2015-2020 dengan menggunakan database Google Scholar. Hasil penelusuran kemudian dianalisis dan disimpulkan.

Studi literatur ini melalui penelusuran hasil publikasi ilmiah dengan rentang tahun 2015-2020 dengan menggunnakan database Google Scholar dengan menggunakan keyword Penerimaan diri "OR" Self Acceptance "AND" Stres "AND" ulkus diabetik. Pada pencarian Google Scholar dilakukan skrining tahun (2015-2020) dan menggunakan frase "penerimaan diri dan stres pada pasien ulkus diabetik" dan "penerimaan diri dan stres pada diabetes melitus".

Berdasarkan hasil penelusuran literatur pada Google Scholar didapatkan 7 lieratur ilmiah meliputi jurnal dan naskah publikasi ilmiah yang sesuai dan relevan dengan variabel stres dengan penerimaan diri pada pasien ulkus diabetik. 
HASIL

\begin{tabular}{|c|c|c|c|c|c|c|}
\hline $\begin{array}{c}\mathrm{N} \\
\mathrm{o}\end{array}$ & Peneliti dan Judul & $\begin{array}{c}\text { Tujuan } \\
\text { Penelitian }\end{array}$ & $\begin{array}{l}\text { Desain } \\
\text { Peneliti } \\
\text { an }\end{array}$ & Responden & $\begin{array}{l}\text { Pengumpul } \\
\text { an data }\end{array}$ & Hasil penelitian \\
\hline 1 & $\begin{array}{l}\text { Rosi Indriani, } \\
\text { Ahmad Asyrofi, } \\
\text { Setianingsih. } \\
\text { Kendal (2017) } \\
\text { Studi Kejadian } \\
\text { Ulkus Diabetikum } \\
\text { dan Tingkat Stres } \\
\text { Klien Diabetisi }\end{array}$ & $\begin{array}{l}\text { Untuk } \\
\text { mengetahui } \\
\text { hubungan } \\
\text { antara } \\
\text { kejadian ulkus } \\
\text { diabetikum } \\
\text { dengan stres } \\
\text { tingkat klien } \\
\text { pada diabetisi. } \\
\text { diabe }\end{array}$ & $\begin{array}{l}\text { Cross- } \\
\text { Section } \\
\text { al }\end{array}$ & $\begin{array}{l}\text { Sampe1 } \\
\text { diambil } \\
\text { secara } \\
\text { accidental } \\
\text { sampling } \\
\text { sebanyak } 49 \\
\text { orang }\end{array}$ & $\begin{array}{l}\text { Instrumen } \\
\text { penelitian } \\
\text { menggunak } \\
\text { an penilaian } \\
\text { derajat } \\
\text { ulkus } \\
\text { menurut } \\
\text { Wagner dan } \\
\text { kuesioner } \\
\text { Diabetes } \\
\text { Distres } \\
\text { Scale (DDS) }\end{array}$ & $\begin{array}{l}\text { Hasil penelitian } \\
\text { menunjukan hubungan } \\
\text { antara lama ulkus } \\
\text { diabetikum dengan } \\
\text { tingkat stres pada klien } \\
\text { diabetisi, dan terdapat } \\
\text { hubungan derajat ulkus } \\
\text { dengan tingkat stres } \\
\text { pada klien diabetisi }\end{array}$ \\
\hline 2 & 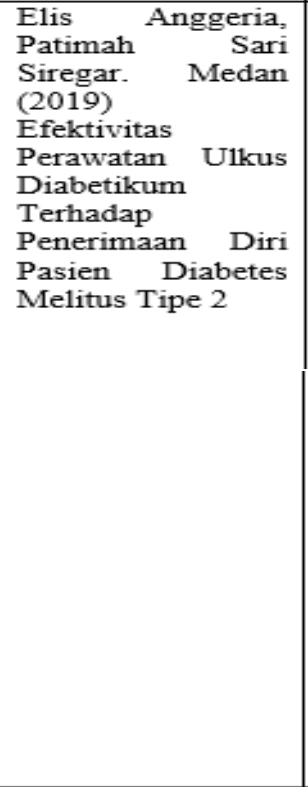 & $\begin{array}{l}\text { Untuk } \\
\text { mengetahui } \\
\text { efektivitas } \\
\text { perawatan } \\
\text { ulkus } \\
\text { diabetikum } \\
\text { terhadap } \\
\text { penerimaan } \\
\text { diri pasien } \\
\text { Diabetes } \\
\text { Melitus Tipe } \\
\text { II di Asri } \\
\text { Wound Care } \\
\text { Wound Care } \\
\text { Centre } \\
\text { Medan. }\end{array}$ & $\begin{array}{l}\text { Quasi } \\
\text { experim } \\
\text { ental } \\
\text { melalui } \\
\text { pendek } \\
\text { atan one } \\
\text { group } \\
\text { pretest } \\
\text { posttest } \\
\text { design }\end{array}$ & $\begin{array}{l}\text { Populasi } \\
\text { sebanyak } 20 \\
\text { orang dan } \\
\text { menggunak } \\
\text { an Teknik } \\
\text { total } \\
\text { sampling }\end{array}$ & $\begin{array}{l}\text { Instrument } \\
\text { penelitian } \\
\text { menggunak } \\
\text { an kuesioner } \\
\text { dan } \\
\text { observasi. } \\
\text { Kuesioner } \\
\text { penerimaan } \\
\text { diri pasien } \\
\text { menggunak } \\
\text { an Diabetes } \\
\text { Acceptance } \\
\text { Scale (DAS) } \\
\text { Scale (DAS) }\end{array}$ & 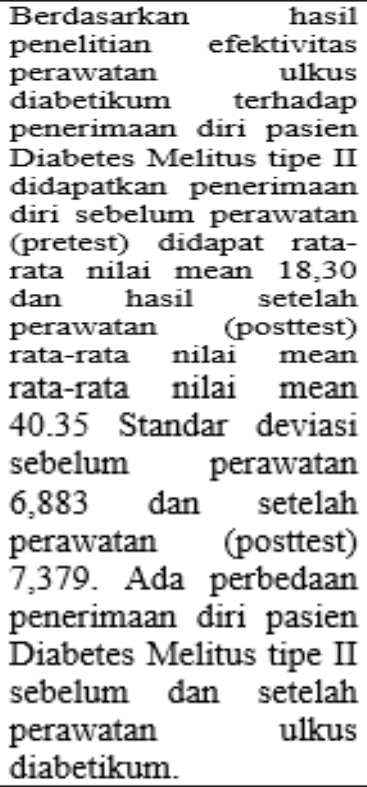 \\
\hline 3 & \begin{tabular}{lr}
\multicolumn{2}{l}{ Luthfi Nur Azhari. } \\
Semarang (2016) \\
Manajemen & Stres \\
Pasien & dengan \\
Ulkus & Kaki \\
DIabetikum & di \\
RSUD & Kota \\
Semarang &
\end{tabular} & $\begin{array}{l}\text { Untuk } \\
\text { mengetahui } \\
\text { manajemen } \\
\text { stres pada } \\
\text { pasien dengan } \\
\text { ulkus kaki } \\
\text { diabetikum di } \\
\text { RSUD Kota } \\
\text { Semarang. }\end{array}$ & $\begin{array}{l}\text { Cross- } \\
\text { section } \\
\text { al }\end{array}$ & $\begin{array}{l}\text { Sampel } \\
\text { dalam } \\
\text { penelitian } \\
\text { ini terdapat } \\
\text { sebanyak } \\
125 \text { pasien } \\
\text { dengan } \\
\text { Teknik } \\
\text { sampling } \\
\text { purposive } \\
\text { sampling }\end{array}$ & $\begin{array}{l}\text { Instrument } \\
\text { penelitian } \\
\text { yang } \\
\text { digunakan } \\
\text { yaitu berupa } \\
\text { kuesioner } \\
\text { manajamen } \\
\text { stres }\end{array}$ & $\begin{array}{lr}\text { Hasil } & \text { penelitian } \\
\text { menunjukkan } & \text { sebesar } \\
69,6 \% & \text { responden } \\
\text { melakukan manajemen } & \text { majem } \\
\text { stres dengan } & \text { kategori } \\
\text { cukup } & \text { baik. } \\
\text { Ditunjukkan } & \text { dengan } \\
\text { sebagian } & \text { besar } \\
\text { responden rutin kontrol } \\
\text { ke pelayanan kesehatan, } \\
\text { melakukan } \\
\text { berkumpul ibadah, } \\
\text { keluarga, } & \text { bersama } \\
\text { menerima } & \text { dapat }\end{array}$ \\
\hline
\end{tabular}




\begin{tabular}{|c|c|c|c|c|c|c|}
\hline & & & & & & $\begin{array}{l}\text { kesehatan, memperoleh } \\
\text { dukungan langsung dari } \\
\text { keluarga dalam } \\
\text { perawatan ulkus, dan } \\
\text { optimis terhadap } \\
\text { kondisi kesehatannya }\end{array}$ \\
\hline \begin{tabular}{|l|}
4 \\
\end{tabular} & 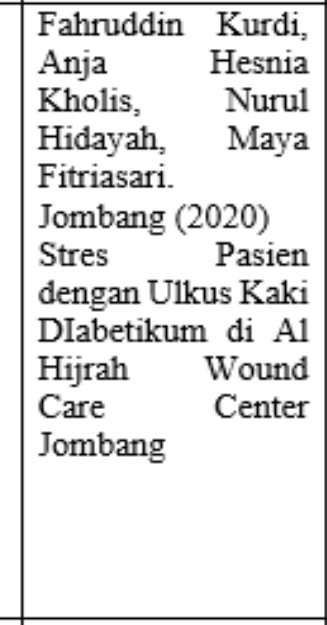 & $\begin{array}{l}\text { Untuk } \\
\text { mengetahui } \\
\text { bagaimana } \\
\text { stres yang di } \\
\text { alami } \\
\text { penderita } \\
\text { ulkus kaki } \\
\text { diabetikum }\end{array}$ & $\begin{array}{l}\text { Kualitat } \\
\text { if } \\
\text { dengan } \\
\text { pendek } \\
\text { atan } \\
\text { fenomo } \\
\text { logi }\end{array}$ & $\begin{array}{l}\text { Sampel } \\
\text { sebanyak } 2 \\
\text { pasien yang } \\
\text { melakukan } \\
\text { perawatan } \\
\text { luka di al } \\
\text { hijrah } \\
\text { wound care }\end{array}$ & \begin{tabular}{|l} 
Data \\
diambil \\
dengan \\
wawancara \\
secara \\
mendalam \\
serta \\
observasi
\end{tabular} & \begin{tabular}{|lr} 
Penelitian \\
menghasilkan bahwa \\
stres akibat ulkus \\
diabetikum adalah suatu \\
kondisi r yang \\
mempunyai pengaruh \\
terhadap kondisi fisik \\
maupun psikis dan \\
menyebabkan pasien \\
mengalami stres antara \\
lain: gangguan citra \\
tubuh, r kesulitan \\
bergerak, takut di \\
amputasi ran \\
keterbatasan dana \\
perawatan biaya
\end{tabular} \\
\hline 5 & 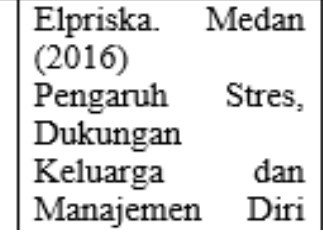 & $\begin{array}{l}\text { Untuk } \\
\text { mengetahui } \\
\text { pengaruh } \\
\text { stres. } \\
\text { dukungan } \\
\text { keluarga dan }\end{array}$ & $\begin{array}{l}\text { Cross- } \\
\text { Section } \\
\text { al }\end{array}$ & $\begin{array}{l}\text { Sampel } \\
\text { penelitian } \\
\text { adalah } \\
\text { adis DM } \\
\text { pasien D } \\
\text { tipe } 2 \\
\text { dengan dan }\end{array}$ & \begin{tabular}{|l|} 
Data \\
diambil \\
dengan \\
menggunak \\
an kuesioner
\end{tabular} & $\begin{array}{lr}\text { Hasil penelitian ini } \\
\text { menunjukkan tercapat } \\
\text { pengaruh } & \text { stress, } \\
\text { dukungan keluarga dan } \\
\text { manaiemen r diri. } \\
\text { terhadar komplikasi }\end{array}$ \\
\hline & \begin{tabular}{|lr}
\multicolumn{3}{|l}{ Terhadap } \\
Komplikasi Ulkus \\
Kaki $\quad$ DIabetik \\
pada & Penederita \\
DM Tipe 2
\end{tabular} & $\begin{array}{l}\text { manaiemen } \\
\text { diri terhadap } \\
\text { komplikasi } \\
\text { ylkus kaki } \\
\text { diabetik pada } \\
\text { penderita DM } \\
\text { tipe } 2\end{array}$ & & \begin{tabular}{|l} 
tanpa \\
komplikasi \\
ylkus kaki \\
diabetik. \\
yang \\
beriummlah \\
80 orang \\
pasien 40 \\
orang kasus \\
dan 40 \\
orang \\
kontrol) \\
yang \\
diambil \\
dengan \\
teknnik \\
purposive \\
sampling
\end{tabular} & & $\begin{array}{l}\text { ylkus kaki diabetik pada } \\
\text { penderita DM tipe } 2 \text {. } \\
\text { Sedangkan variabel } \\
\text { yang paling } \\
\text { mempengaruhi } \\
\text { teriadinya komplikas } \\
\text { ulkus kaki diabetik pada } \\
\text { penderita DM tipe } 2 \\
\text { adalah stres yang tinggi }\end{array}$ \\
\hline 6 & $\begin{array}{l}\text { Rosalia Da Costa } \\
\text { Mendes, Gipta } \\
\text { Galih Widodo, M. } \\
\text { Imron Rosidi. } \\
\text { Ungaran (2019) } \\
\text { Hubungan } \\
\text { Dukungan } \\
\text { Keluarga Terhadap } \\
\text { penerimaan Diri } \\
\text { Pasien yang } \\
\text { Mengalami Ulkus } \\
\end{array}$ & \begin{tabular}{|l|} 
untuk \\
mengetahui \\
hubungan \\
dukungan \\
keluarga \\
dengan \\
penerimaan \\
diri pasien \\
yang \\
mengalami \\
ulkus \\
\end{tabular} & \begin{tabular}{|l} 
Deskrip \\
tif \\
korelati \\
$\mathrm{f}$
\end{tabular} & $\begin{array}{l}\text { Populasi } \\
\text { penelitian } \\
\text { ini adalah } 32 \\
\text { pasien, } \\
\text { dengan } \\
\text { pengambila } \\
\text { n sampel } \\
\text { menggunak } \\
\text { an total } \\
\text { sampling }\end{array}$ & $\begin{array}{l}\text { Data } \\
\text { diambil } \\
\text { dengan cara } \\
\text { membagika } \\
\text { n kuesioner } \\
\text { kepada } \\
\text { sampel }\end{array}$ & $\begin{array}{l}\text { Penelitian ini } \\
\text { menunjukkan sebagian } \\
\text { besar pasien Dm dengan } \\
\text { ulkus yang memiliki } \\
\text { dukungan keluarga } \\
\text { kategori baik, yaitu } \\
\text { sejumlah } 27 \text { orang dan } \\
\text { sebagian besar pasien } \\
\text { Dm dengan ulku yang } \\
\text { smemiliki penerimaan } \\
\text { diri kategori baik, yaitu }\end{array}$ \\
\hline
\end{tabular}




\section{PEMBAHASAN}

Stres adalah respon tubuh yang tidak spesifik terhadap setiap kebutuhan tubuh yang terganggu, suatu fenomena universal yang senantiasa terjadi dalam kehidupan dan tidak dapat dihindari, dan setiap orang mengalaminya. Stres dapat berdampak secara total terhadap fisik, psikologis, intelektual, sosial, spiritual individu, dan stres juga mengancam keseimbangan fisiologis (Potter \& Perry, 2009 dalam Indriani, 2017). Dilansir dari jurnal milik Silalahi tahun 2018, penerimaan diri adalah Individu bebas dari rasa bersalah, rasa malu, dan rendah diri karena keterbatasan diri serta kebebasan dari kecemasan akan adanya penilaian dari orang lain terhadap keadaan dirinya (Hjelle \& Ziegler, 1992). Sedangkan Ulkus kaki diabetik adalah luka yang dialami oleh penderita diabetes pada area kaki dengan kondisi luka mulai dari luka superficial, nekrosis kulit, sampai luka dengan ketebalan penuh (full thickness), yang dapat meluas ke jaringan lain seperti tendon, tulang dan persendian. Jika ulkus dibiarkan tanpa penatalaksanaan yang baik akan mengakibatkan infeksi atau gangren (Fernando, 2014 dalam Hasena, 2019)

Pada penelitian oleh Elpriska tahun 2016 berjudul pengaruh stres, dukungan keluarga dan manajemen diri terhadap komplikasi ulkus kaki diabetik pada penderita DM tipe 2 didapatkan dari ketiga variabel yang diteliti, stres merupakan variabel yang paling berpengaruh terhadap ulkus diabetik karena stres akan menurunkan kemampuan pengontrolan gula darah dan kemandirian akan perawatan diri, yang mana akan memicu komplikasi diantara lain ulkus diabetik. Dalam jurnal ini juga didapatkan bahwa ada pengaruh dukungan keluarga terhadap ulkus diabetik, dan pentingnya dukungan keluarga tersebut dalam keberhasilan pengobatan penderita.

Keluarga tentu saja memegang peran yang sangat penting terhadap banyak aspek kehidupan anggotanya. Disebutkan pada penelitian yang berjudul hubungan antara dukungan keluarga dengan tingkat stres psikologis pada pasien ulkus DM di RSUP Dr. Soeradji Tirtonegoro Klaten, semakin tinggi dukungan keluarga maka akan semakin rendah tingkat stres psikologis yang dialami oleh pasien dengan ulkus diabetik, yang berarti keluarga memiliki andil besar dalam kesejahteraan psikologis anggotanya yang sakit.

Berdasarkan wawancara pada penelitian yang dilakukan di al hijrah wound care center jombang tentang stres pada pasien ulkus diabetik (2020) didapatkan 4 penyebab pasien merasa stres. Yang pertama yaitu stres karena gangguan citra tubuh, responden merasa malu dan takut untuk berinteraksi dengan orang lain. Menurut mereka dengan kondisi fisik yang sekarang, orang lain akan memandang rendah dan menjadikan mereka bahan ejekan karena perubahan bentuk fisik yang terjadi, menjadikan mereka lebih memilih di dalam rumah dan tidak berinteraksi dengan orang lain. Yang kedua yaitu stres karena kesulitan bergerak. Salah satu responden menyatakan bahkan untuk ke kamar saja ia harus dibantu. Selanjutnya pasien stres akibat kemungkinan amputasi. Responden mengalami stres ketika disarankan untuk amputasi, juga menyatakan badannya lemas ketika mendengar akan diamputasi dan jantungnya berdegup kencang, pun mengatakan sempat menangis. Yang terakhir yaitu pasien stres akibat keterbatasan biaya. Akibat perawatan yang lama dan biaya yang tidak murah menjadi salah satu penyebab stres muncul, ditambah lagi apabila ekonomi keluarga dalam golongan rendah, menurut responden pemenuhan untuk biaya hidup sehari hari sudah sulit ditambah dengan biaya yang harus dikeluarkan oleh keluarga akan menjadikan beban pikiran. Kemudian perihal upaya melakukan ritual atau perilaku tertentu agar stres berkurang, responden mengiyakan bahwa melakukan ibadah sebagai pereda stres. Adapun upaya lain yang dilakukan yaitu mencari pertolongan tenaga kesehatan. Disimpulkan bahwa setelah mengetahui kondisi kesehatannya, responden merasa lebih tenang. Karena penelitian ini menggunakan metode wawancara, hasil-hasil yang didapatkan lebih detail dan mendalam.

Penanganan stres penderita ulkus lainnya disebutkan pada peneltian oleh Azhari (2016) bahwa aktivitas yang dilakukan untuk menghilangkan atau meminimalkan stres yaitu selalu menjaga agar penyakitnya tidak semakin parah dengan rutin kontrol ke pelayanan kesehatan, melakukan ibadah saat sedang stres, serta berkumpul bersama keluarga agar stres berkurang

Terkait mencari pertolongan tenaga kesehatan upaya meredakan stres, penderita ulkus diabetikum dengan penerimaan diri rendah juga membenarkan bahwa perawatan oleh tenaga kesehatan dapat meningkatkan tingkat penerimaan diri. Penelitian dilakukan oleh Anggeria dan Siregar (2019) setelah dilakukan perawatan terhadap ulkus, 17 dari 20 responden menyatakan penerimaan dirinya membaik. Penelitian ini merupakan penelitian quasy eksperimen dan dapat membuktikan bahwa perawatan luka ulkus efektif meningkatkan tingkat penerimaan diri penderita. Hanya saja kekurangannya tidak dijelaskan metode perawatan luka seperti apa yang digunakan.

Sebelumnya sempat disebutkan bahwa berkumpul bersama keluarga dapat meredakan stres penderita ulkus diabetik. Kemudian pada penelitian oleh Mendes (2019) terkait hubungan dukungan keluarga terhadap penerimaan diri pasien ulkus diabetik dikatakan bahwa pasien dengan penerimaan diri baik, dukungan keluarga yang didapatkan juga 
cenderung baik. Hal ini dikarenakan keluarga sebagai orang terdekat, senantiasa memberikan semangat dan dukungan yang mana akan berpengaruh positif terhadap psikologis penderita ulkus diabetik termasuk stres dan penerimaan diri.

Hal lain yang didapatkan adalah pada penelitian tentang studi kejadian ulkus diabetik dengan tingkat stres oleh Indriani, Asyrofi, dan Setianingsih (2017) menunjukkan bahwa semakin lama menderita ulkus maka semakin tinggi tingkat stres yang dialami oleh diabetisi. Penelitian ini juga menunjukan semakin berat derajat ulkus, maka semakin tinggi tingkat stres yang dialami oleh klien diabetisi. Namun kekurangan pada jurnal ini tidak disebutkan penanganan stres yang digunakan oleh pasien.

\section{KESIMPULAN}

Berdasarkan penjabaran dari 7 jurnal yang berkaitan dengan judul dari penelitian ini yaitu "hubungan stres dan penerimaan diri pada pasien ulkus diabetik", peneliti dapat mengambilan kesimpulan bahwa stres dan penerimaan diri mempunyai hubungan yang kuat dan saling mempengaruhi. Hal ini dikarenakan penderita ulkus diabetik yang keadaan tubuhnya melemah menjadi rentan terhadap stres sehingga menjadikan ulkus diabetik tadi sebagai stresor yang memicu stres, selanjutnya dampak stres membuat persepsi terhadap diri pasien sendiri menjadi kurang baik dan menurunkan kualitas penerimaan dirinya. Kemudian berdasarkan penelitian-penelitian di atas, ibadah, melakukan kontrol terhadap kondisi penyakit, dan keluarga (seperti misalnya berkumpul bersama) berpengaruh besar dalam penyembuhan pasien dan juga merupakan metode-metode yang digunakan untuk mengurangi stres dan meningkatkan penerimaan diri pasien.

\section{B. Saran}

1. Bagi peneliti selanjutnya diharapkan meneliti lebih lanjut peran keluarga terhadap penanganan stres maupun terhadap penerimaan diri ataupun keduanya secara bersamaan, serta dampaknya pada pasien diabetes melitus dengan dan tanpa komplikasi ulkus diabetik

2. Bagi tenaga kesehatan disarankan mengkaji lebih lanjut jika pasien ulkus menunjukkan tandatanda stres dan penerimaan diri kurang, serta memberikan tindakan yang sesuai jika dirasa perlu

\section{DAFTAR PUSTAKA}

Anggeria, Elis., Siregar, S Patimah. (2019). Efektivitas perawatan ulkus diabetikum terhadap penerimaan diri pasien diabetes melitus tipe II. Jurnal JUMANTIK, vol 4, no 2, 178-189

Aulia, Khairiyatul., Permana, Iman., Primanda, Yanuar. (2018). Penerimaan Diri pada Penderita Diabetes Melitus Paska Amputasi di Wilayah Lombok Nusa Tenggara Barat. The Shine Cahaya Dunia Ners, Volume 3, No. $1.19-32$

Azhari, N. Luthfi. (2016). Manajemen stres pasien dengan ulkus kaki diabetikum di RSUD kota semarang. (skripsi). Universitas diponegoro, semarang.

Badan Penelitian dan Pengembangan Kesehatan. (2018). Laporan Nasional Riskerdas 2018. Jakarta: Lembaga Penerbit Badan Penelitian dan Pengembangan Kesehatan.

Chaplin, James P. (2012). Kamus Lengkap Psikologi. Jakarta: Rajawali Pers.

Elpriska. (2016). Pengaruh stres, dukungan keluarga dan manajemen diri terhadap komplikasi ulkus kaki diabetik pada penderita DM tipe 2. Idea Nursing Journal. Volume 7. No. 1. 20-25

Handayana, A. Yuda. (2015). Tepat dan jitu: atasi ulkus kaki diabetes. Yogyakarta: Rapha Publishing.

Hurlock, E, B. (2011). Psikologi Perkembangan Suatu Pendekatan Sepanjang Rentang Kehidupan,. Jakarta: Erlangga. IDF. (2019). IDF Diabetes Atlas Ninth Edition 2019.

IDF, 2020, Type 1 Diabetes [online]. Dari: https://www.idf.org/aboutdiabetes/what-is-diabetes/type-1-diabetes.html. Diakses 28 Januari 2020 pukul 21:44 WITA

Indriani, Rosi., Asyrofi, Ahmad., Setianingsih. (2017). Studi kejadian ulkus diabetikum dan tingkat stres klien diabetisi. Jurnal keperawatan, volume 9, no 1,30-37. 
Ispriantari, Aloysia., Priasmoro, Dian Pitaloka. (2017). Penerimaan Diri pada Remaja dengan Diabetes Tipe 1 di Kota Malang. Dunia Keperawatan. Volume 5, nomor 2, 115-120.

Karyono, W. D. Yhani. (2012). Korelasi Antara Penerimaan Diri dengan Stres pada Penderita Diabetes Melitus Tipe 2.

Kurdi, Fahruddin., Kholis, H Anja., Hidayah, Nurul., Fitriasari, Maya. (2020). Stres pasien Dengan ulkus kaki diabetikum di al-Hijrah wound care center jombang. Jurnal ilmiah keperawatan, vol 6, no. 1,

Machfoedz, Ircham. (2013). Metodologi Penelitian (kuantitatif \& kualitatif). Yogyakarta: Penerbit Fitramaya

Maghfuri, Ali. (2016). Buku pintar perawatan luka diabetes melitus. Jakarta: Salemba Medika.

Mendes, D. C. Rosalia. (2019) hubungan dukungan keluarga terhadap penerimaan diri pasien yang mengalami ulkus diabetikum di RSUD ungaran.

Muhammad Ridha. (2012). Hubungan Antara Body Image dengan Penerimaan Diri pada Mahasiswa Aceh di Yogyakarta. Empathy, Volume 1, No. 1,111-121.

Mulis, S. Moh. (2015). Tingkat stres pada pasien ulkus diabetikum di majapahit wound care mojokerto.

Noor, M. Hasnah, dkk. (2019). Metodologi Penelitian. Makassar: Unit Penelitian Poltekkes Makassar

PERKENI. (2015). Konsensus pengelolaan dan pencegahan diabetes melitus tipe 2 di Indonesia. Jakarta: Pengurus Besar Perkumpulan Endokrinologi Indonesia.

Permatasari, Vera., Gamayanti, Witrin. (2016). Gambaran penerimaan diri pada orang yang mengalami skizofrenia. Psympatic, Jurnal IImiah Psikologi. Volume 3, No. 1. 139-152

Prasetyono, O. H. Theddeus. (2016). Panduan Klinis Manajemen Luka. Jakarta: EGC

Rumahorbo, Hotma. (2014). Asuhan keperawatan klien dengan gangguan sistem endokrin. Jakarta: EGC.

Rusminigsih, Esri., Satria, Ganang. (2017). Hubungan Antara Dukungan Keluarga dengan Tingkat Stres Psikologis pada Pasien Ulkus Diabetes Melitus di RSUP Dr. Soeradji Tirtonegoro Klaten. The 6th University Colloquium 2017 Universitas Muhammadiyah Malang. Volume 6. 521-528

Silalahi, L Kristina., Patriona, Nunik. (2018). Hubungan Body Image dengan Self-Acceptance (Penerimaan Diri) pada Pasien Ulkus Diabetikum di Rumah Sakit TK II Putri Hijau Kota Medan. Jurnal Keperawatan Priority, Vol 1, No. 1.

Sinaga, Rika Nailuvar. (2016). Diabetes Melitus dan Olahraga. Volume 1, No. 2, 21-29.

Smeltzer, Suzanne C. (2013). Buku ajar keperawatan medical-bedah Brunner \& Suddarth. Jakarta: EGC.

Soegondo, Sidartawan, dkk. (2018) Penatalaksanaan Diabetes Melitus Terpadu. Jakarta: Balai Penerbit FKUI.

Sugiyono. (2019) Metode Penelitian Pendidikan. Bandung: Alfabeta

Tarwoto. (2016). Keperawatan medikal bedah: Gangguan sistem endokrin. Jakarta: Trans Info Media.

Ulina, O Maria., Kurniasih, I Olivia., Putri, E Dona. (2013) Hubungan Religiusitas dengan Penerimaan Diri pada Mayarakat Miskin. Proceeding PESAT. Vol. 5, 17-22

WHO, 2018, Diabetes. [online]. Dari: https://ww.who.int/news-room/fact-sheets/detail/diabetes. Diakses 28 Januari 2020. Pukul 21:27 WITA 